\title{
O Centenário de Eça de Queirós na Imprensa
}

Resumo:

Este artigo busca realizar uma análise não extensiva daquilo que foi escrito na imprensa portuguesa sobre Eça de Queirós na altura do seu primeiro centenário de nascimento, em 1945. São analisados escritos de intelectuais e ideólogos portugueses como António Ferro, António Eça de Queiroz, Vieira de Almeida e Rocha Martins publicados em jornais como o Diário de Notícias, A República e As Novidades. O objetivo do texto é analisar até que ponto, no contexto ditatorial em que se deu o centenário queirosiano, o debate sobre autor oitocentista tornou-se um substituto para os debates interditados pelas várias formas de repressão que dominavam a esfera pública portuguesa.

Palavras-chave:

Eça de Queirós, Salazarismo, Imprensa Portuguesa, 1945, Esfera Pública

Abstract:

This article aims to carry out a non-extensive analysis of what was written in the Portuguese press about Eça de Queirós at the time of its first centenary of birth, in 1945. The analysed texts were written by Portuguese intellectuals and ideologues such as António Ferro, António Eça de Queiroz, Vieira de Almeida and Rocha Martins, and published in newspapers such as Diário de Notícias, A República and As Novidades. The aim of this work is to analyse the extent to which, in the dictatorial context in which the Queirosian centenary took place, the debate about the 19th century author became a substitute for debates banned by the various forms of repression that dominated the Portuguese public sphere.

Keywords:

Eça de Queirós, Salazarism, Portuguese Press, 1945, Public Sphere 


\section{Introdução}

Este artigo é parte de uma investigação mais ampla e ainda em andamento em torno do primeiro centenário de nascimento de Eça de Queirós, celebrado em 1945. Ao longo de todo o processo de pesquisa, a ênfase tem recaído sobre as diversas interpenetrações entre os campos do político e do literário tornadas visíveis quando lançamos olhos sobre essa antiga e já esquecida efeméride. Como se verá brevemente ao longo desse artigo, o ano de 1945 corresponde a um momento chave do regime ditatorial de Oliveira Salazar que governava Portugal desde a década anterior, e as celebrações em torno de Eça de Queirós serão neste contexto instrumentalizadas pelo estado com certos fins políticos. Pude introduzir mais demoradamente essa questão em um trabalho anterior, já publicado.

Neste texto específico, que ora se segue, o enfoque recairá não exatamente sobre as celebrações oficiais promovidas por aparelhos do Estado, mas sobre as respostas que outros atores da política portuguesa tiveram condições de dar ao processo. Para tanto, a análise se limitará ao que foi publicado sobre Eça de Queirós na imprensa portuguesa durante o seu centenário. Não se trata - pelo menos ainda - de uma tentativa de abordar extensivamente esse corpo de textos, mas de analisar com alguma profundidade um corpo seleto de textos representativo do todo, que fornece subsídios para a tese que temos procurado comprovar: no contexto ditatorial em que se deu o centenário queirosiano, o debate sobre autor oitocentista tornou-se um substituto para os debates interditados pelas várias formas de repressão que dominavam a esfera pública portuguesa.

\section{O caso de Vieira de Almeida}

No dia 21 de Novembro de 1945 (quando faltavam apenas quatro dias para o primeiro centenário de nascimento de Eça de Queirós) a segunda página do Diário de Notícias de Lisboa trazia uma nota de três parágrafos anunciando a publicação do pequeno livro À janela de Tormes, da autoria do "ilustre professor dr. Vieira de Almeida". A pequena nota vinha sem qualquer assinatura e entalada entre duas notícias maiores, mas estava no alto da página disputando terreno com temas urgentes da política portuguesa e internacional, o que talvez denote o prestígio que o jornal dava na altura aos assuntos queirosianos. O primeiro parágrafo do texto informava que o volume em questão era a "contribuição" de seu autor para "as comemorações do centenário", na forma de uma "análise mental" de Eça. O texto seguia louvando a "profundeza e a sensibilidade" do "espírito" de Vieira de Almeida, elogiando ainda seus "transcendentais conceitos", sem dizer, contudo, nenhuma informação mais concreta e precisa sobre o teor do livro. O terceiro e último parágrafo da nota, finalmente, contrastava com os dois anteriores em termos de precisão, destacando para o leitor o primeiro dos oito capítulos do livro como algo especialmente importante:

O primeiro capítulo do novo livro do prof. Vieira de Almeida, que serve de introdução, intitula-se 'Geração de Setenta' e é, sem dúvida, o mais admirável panorama que se tem sido traçado da plêiade de valores a que Eça de Queirós pertencia e que dominou a vida intelectual portuguesa 
nos fins do século passado.

(À JANELA... 1945)

O leitor curioso pela Geração de 70 que seguisse a sugestão do mais prestigiado jornal de Lisboa e se concentrasse na leitura do primeiro capítulo de À Janela de Tormes talvez tivesse uma surpresa. Descrevê-lo como um mero "panorama" de uma "plêiade de valores" da Geração de Setenta, como faz a nota, é certamente um gesto parcial, que omite o óbvio tema principal do texto em questão. O tal capítulo intitulado "Geração de Setenta" pouquíssimo se dedica a tratar, em si mesma, da mítica geração que marcou e renovou o pensamento português a partir dos escritos doutrinários, artísticos e polêmicos de autores como Eça de Queirós, Oliveira Martins, Ramalho Ortigão, Antero de Quental, Teófilo Braga e etc. Seu tema principal, é, na verdade, contrapor politicamente certo espírito intelectual associado à Geração de 70 com a atualidade portuguesa de quando a obra foi publicada, isto é, os anos 1940. Ao longo de todo o capítulo do referido livro, Vieira de Almeida defende a tese de que o brilhantismo de Eça e seus companheiros de geração só teria sido possível graças ao clima de liberdade intelectual de que se beneficiavam, e esse "clima" teria se tornado de todo impossível naquele Portugal do ano de 1945. São feitas alusões bem pouco sutis à censura (ao falar das Farpas, Almeida diz que "se hoje fosse possível aparecer publicação análoga, quantas coisas teriam medo de aparecer à clara luz!" [Almeida 1945: 21]), ao autoritarismo (ao falar de Oliveira Martins, diz que "o feriria hoje o desplante com que certos Quixotes se crêem representantes natos de tanta certeza, tanta verdade, tanto dogma" [idem: 25]) e ao nacionalismo "irredutível e transcendente" do presente dos anos quarenta, que contrastaria com o patriotismo de "serena dignidade" da Geração de Setenta (idem: 33). Como se pode facilmente deduzir, esse capítulo específico do livro de Vieira de Almeida constitui uma veemente crítica à ditadura de Oliveira Salazar, disfarçada em um livro sobre Eça de Queirós. Assim sendo, é muito improvável que tenha sido por acaso a recomendação precisamente desse trecho por parte do autor da notinha anônima no Diário de Notícias.

Suponho que estamos, neste caso, diante de um sutilíssimo mas ilustrativo ato de rebeldia cometido por um jornalista cujo nome a história não preservou. Valendo-se da aparente neutralidade e respeitabilidade de um tema como o centenário de Eça, a figura em questão deu alguma publicidade para um texto de evidente caráter subversivo e contrário à ditadura, driblando não apenas a censura e a perseguição política mas também própria orientação ideológica do Diário de Notícias. O Diário era ordinariamente um veículo de imprensa tão simpático às diretrizes do Estado Novo que chegou a ser descrito como um "órgão oficioso do regime" (Tengarrinha 2006: 214).

A escolha de começar este artigo com esse pequeno caso anedótico advém do fato de que o julgo representativo de um fenômeno sistemático. A suposição a ser trabalhada neste texto é a de que tenha havido, em 1945, uma espécie de colaboração entre elementos da imprensa e da intelectualidade portuguesa para aproveitar o centenário de nascimento de Eça de Queirós como elemento coesivo em torno do qual se pudesse articular um debate sobre temas que o regime de Salazar pretendia interditar. Pode-se ler este artigo como uma tentativa de diálogo 
com o livro O Último Eça, publicado em 2005 por Miguel Real, no qual o autor repreende com talvez demasiado rigor os comentadores queirosianos à volta do centenário por terem feito "projecção, em forma de preconceito ideológico [...] de visões exteriores e anacrónicas sobre o interior da obra de Eça" (Real 2005: 126), e talvez perca aí de vista o principal. Real denuncia o que julga ser uma espécie de inserção ilícita e apriorística de certas ideias políticas em ensaios interpretativos sobre Eça de Queirós como o de Vieira de Almeida; supõe tacitamente, assim, que houvesse em contrapartida um foro lícito no qual essas idéias pudessem circular; algo que se assemelhasse àquele modelo ideal de "esfera pública" proposto por Habermas, capaz de abarcar debates independentes, desinteressados e de interesse público (cf. Habermas 1991). A hipótese que pretendo defender aqui (dando razão, aliás, ao próprio Vieira de Almeida e seus comentários mordazes sobre a censura) é a de que a esfera pública no Portugal dos anos 1940 jamais poderia ser constituída de uma forma tão estável, quando levamos em conta o projeto autoritário e de pretensões totalitárias que marcou o Estado Novo salazarista (cf. Rosas 2018). Os intelectuais portugueses que porventura pretendessem discutir política portuguesa, ou temas mais abrangentes ligados a Portugal, dependiam sempre da constituição de esferas públicas precárias, provisórias e camufladas, no interior das quais debates como esses pudessem se dar. ${ }^{1}$ Espero neste texto angariar subsídios para provar que o centenário de Eça de Queirós foi, naquele ano de 1945, uma dessas precárias esferas públicas.

\section{O caso das Novidades}

Curiosamente, o primeiro caso de que pretendo tratar não corresponde à narrativa clássica da militância anti-salazarista subversivamente inoculando seu discurso oposicionista em debates culturais, como o exemplo de Vieira de Almeida acima. O primeiro esforço no sentido de tornar o Centenário de Eça de Queirós uma espécie de subterfúgio para romper a homogeneidade do discurso oficial salazarista partiu do interior tensionado do próprio salazarismo, mais especificamente do grupo de ideólogos ultracatólicos que consistia em uma das mais importantes bases ideológicas e políticas do regime.

Quando António Ferro, diretor do SNI, anunciou pela primeira vez sua intenção de promover uma grande celebração do centenário de Eça, ainda em 20 de Novembro de 1944, o fez em uma entrevista para o mesmo Diário de Notícias, que deixava muito clara a imagem do autor que a propaganda intentaria promover oficialmente pelo Estado. "Não há dúvida de que Eça de Queirós foi um escritor revolucionário", declara Ferro (Ferro 1944). O chefe da propaganda salazarista defende que, num tempo em que "o nacionalismo como expressão política ainda não se teria definido", Eça de Queirós teria sido um "renovador" que "aproximou-se, afinal, do que queríamos, até - ou sobretudo - quando destruía" (Ferro 1944). O uso da primeira pessoa do plural em "queríamos" enfatiza que neste momento Ferro quer falar em nome do regime como um todo, assumindo o ponto de vista da própria ideologia. Sua hipótese, como se pode ver pelo trecho "até - e sobretudo - quando destruía", é assumir orgulhosamente toda a obra de Eça como algo positivo, especialmente a rebeldia iconoclasta, o caráter moralmente transgressivo e a ironia corrosiva que o tornaram célebre (esta seria a parcela "destrutiva" 
da literatura queirosiana). Estes aspectos parecem ser aqui tomados como forças que teriam aberto caminho através do regime oligárquico da Monarquia Constitucional portuguesa "destruindo-a" simbolicamente - para que o "nacionalismo" salazarista aparecesse depois como algo a ser construído no lugar. Em coerência com essa valorização integral da obra de Eça, Ferro anunciava na entrevista que o SNI (Secretariado Nacional de Informação) comandaria a iniciativa da reedição das obras completas do autor.

No início de janeiro de 1945, Ferro deu prosseguimento ao projeto anunciado quando declarou aberto um "concurso de ilustrações" para a tal reedição das obras de Eça. Foi a deixa para que o jornal católico As Novidades - que costumava ser um órgão de apoio exaltado do governo de Salazar - respondesse a Ferro com um veemente editorial, no dia 12 de Janeiro. Nele, Eça de Queirós era atacado como um "ironista blasfemo", capaz de exercer uma "influência nefasta nas mentalidades e nos costumes portugueses" (CONCURSO PARA... 1945). Já está implícito neste primeiro texto aquilo que logo ficará claro e não é difícil de adivinhar: o que incomoda aos católicos em Eça de Queirós é sobretudo a articulação entre a militância anticlerical, certo socialismo proudhoniano e o erotismo bastante explícito que marcaram algumas das obras mais famosas do escritor, como 0 Crime do Padre Amaro e A Relíquia, mas também 0 Primo Basílio e Os Maias. Para os católicos, o caso queirosiano é ainda pior pelo fato de o autor ter recorrido para divulgar tais ideias - a seus recursos enquanto "ironista" e "artista extraordinário", isto é: o romancista neste caso incomodaria tanto por sua forma quanto por seu conteúdo. Trata-se, para As Novidades, de uma figura sob todos os aspectos ímpia, e o Estado Novo ainda assim insistiria, através da reedição de suas obras, em "vulgarizá-lo, facilitá-lo às massas, fazê-lo chegar barato e bem ornado, ao seio das famílias" (ibidem). O tom paranóico do texto - aliás uma marca do discurso cultural fascista, como lembra Vladimir Safatle (Safatle 2019: 12) - é inteiramente afinado com aquele que dominara o país no pré-guerra: a recorrente narrativa de que era necessária vigilância constante no campo da cultura para que certos discursos supostamente impregnados nos bens ali em circulação não desvirtuassem os "valores nacionais".

A resposta ao ataque do jornal católico não vem do próprio Ferro, mas sim do seu braço direito: ninguém menos que António Eça de Queiroz, um dos filhos do escritor, que ocupava a posição de subdiretor do SNI. É com a autoridade filial e governamental que em 18 de Janeiro António Eça responde aos ultracatólicos no jornal Diário Popular, reservando a eles o mesmo tom violento que marcara até então todas as suas réplicas a críticos do pai que o desagradassem. Insinua que o autor não nomeado do editorial das Novidades seria um "aleijado intelectual" e utiliza a si próprio como argumento: se Eça de Queirós fosse de fato um arauto da "imoralidade", do "anti-cristianismo", dos discursos "internacionalistas e anarquisantes", um "anti-nacionalista e anti português" - em suma, "um homem que se tornou perigoso para a Sociedade, pervertendo-a com a sua imoralidade" - como seria possível que seus filhos - e António mais que todos - tivessem se tornado "católicos praticantes, patriotas e nacionalistas intransigentes" (Queiroz 1945-a)? António Eça não está mentindo: terá sido de fato um apoiador fervoroso não apenas de Salazar, mas dos fascismos europeus em geral, "germanófilo" durante a guerra, admirador das figuras de Hitler e Mussolini. De um ponto de vista interpretativo, contudo, para 
além desse argumento biográfico sob todos os aspectos falacioso, o filho em nada avança no debate sobre a obra do pai. Apenas repisa o argumento de Ferro de que Eça de Queirós "criou", com a sua obra iconoclasta, "o ponto de partida para o grande movimento" de reação nacionalista no Estado, na Igreja e etc (Queiroz 1945-a).

Aqui dá-se um lance relevante: a tréplica do jornal As Novidades, que deveria sair na edição de 19 de janeiro respondendo à resposta violenta de António Eça, é censurada. Não é exagero ver neste fato um índice da disposição que o SNI tinha de calar o debate com os católicos, ignorar suas críticas e seguir com o plano de celebração original. Entretanto, o gesto arbitrário que talvez tivesse funcionado contra um jornal republicano sai neste caso pela culatra: a imprensa católica como um todo, incluindo uma série de jornais de província, passa a apoiar de forma solidária as Novidades, publicando uma série de editoriais que repetem ponto a ponto os argumentos contra Eça que aqui chamei de "paranóicos" - segundo os quais as páginas queirosianas pintariam "quadros excessivamente realistas" (segundo A Voz do Pastor), seriam "subversivas" (segundo as Notícias de Covilhã) e "um repertório fundo de lubricidades" (segundo as Notícias de Beja), compondo obras "notoriamente imorais e blasfemas e, como tais proibidas pela igreja de ser lidas pelos fiéis" (segundo A Defesa de Évora) (ADESÕES... 1945).

Diante da subida de tom e da manifestação coletiva de força, a censura recua e libera o editorial das Novidades. António Eça continua a publicar suas cartas abertas defendendo a existência de um caráter integralmente nacionalista na obra do pai, mas já está derrotado. A prova é o fato de que partirá dele, em julho daquele ano, a iniciativa de censurar a forma como seria retratado o incesto no quinto ato da peça Os Maias, uma adaptação do romance queirosiano que estreou no Teatro D. Maria II como parte das comemorações oficiais do centenário. Em uma carta para o delegado do governo responsável pelo Teatro, António Eça impede a estreia da peça a não ser que "no final do trabalho" se faça "um retoque, de máxima importância, para evitar graves dissabores com a Igreja e os jornais católicos" (Queiroz 1945-b). Passou a temer seus adversários.

O principal fator que acelerou o fim da polêmica entre os jornais católicos e o SNI, entretanto, foi o fato de que o próprio editorial inicialmente censurado das Novidades oferecia ao governo uma solução de compromisso, uma saída honrosa que os livrava da pecha de promoverem com os recursos de "um organismo do Estado" um dos "envenenadores" que "perverteram a inteligência e a sensibilidade da Nação" (AINDA O CASO... 1945). Quase ao fim de mais esse violento editorial, o jornal faz duas perguntas e imediatamente as responde: "É nacionalista a última fase de Eça de Queirós? Se é, não se diga que não é. Mas a primeira é socialista, anárquica, jacobina, anti-patriótica? Haja pelo menos a cautela de não a relembrar" (ibidem).

Essa divisão cronológica da obra de Eça em duas partes permite que o Estado Novo continue celebrando o autor - dependendo, para isso, apenas de uma sútil correção de rumo: não se trata mais de celebrar o "revolucionário" que abriu caminho para o salazarismo quando "destruía" com sua iconoclastia a Monarquia Constitucional portuguesa. ${ }^{2}$ Trata-se agora de celebrar em Eça uma espécie de reedição do mito bíblico do filho pródigo que volta ao lar: o escritor que, após uma juventude devotada a "envenenar" a nação, teria se redimido em suas 
obras finais e tornado-se o autor de obras supostamente nacionalistas como A Cidade e as Serras e A Ilustre Casa de Ramires. Uma tal narrativa não seria estranha ao SNI, que já havia promovido com o filme A Revolução de Maio o mito do militante anti-nacionalista (neste caso um bolchevista convicto) que se acaba por se converter comovidamente aos valores da pátria, de Deus e da moral.

Em outro momento desta pesquisa, avaliarei detidamente o impacto dessa espécie correção de rumos nas celebrações oficiais queirosianas. Adianto que terá sido imenso. No âmbito deste texto, me parece mais relevante tentar compreender de que maneira a polêmica que acabo de apresentar projeta sobre as questões literárias queirosianas um debate político que se queria interditar. É preciso ter em mente, neste caso, que o ano de 1945 foi fundamental para o salazarismo na medida em que, com a vitória dos Aliados na Segunda Guerra Mundial, tornou-se bastante mais delicada a posição de Salazar enquanto ditador, sujeita a fortes pressões internas e externas pela abertura do seu regime "fascista conservador" (Rosas 2019: 253, 254). O próprio Salazar reconhece que "a bandeira da vitória foi desfraldada e ficou drapejando para o lado da democracia" (Rosas 2017: 224) e anuncia com grande estardalhaço e propaganda uma série de medidas supostamente liberalizantes para o país, como a instituição do Habeas corpus, a amnistia para presos políticos, o abrandamento da censura e as eleições legislativas nas quais pela primeira vez desde o Golpe Militar de 1926 seria permitida a participação da oposição. Ainda que, novamente segundo Rosas, tais medidas não tenham alterado "nada de essencial" no regime (Rosas 2017: 225), tornou-se claro para a direita mais exaltada do regime que seus projetos de uma maior fascistização do país não vicejariam com a mesma facilidade: instituições fascistas como a Legião Portuguesa (a milícia do regime) e a Mocidade Portuguesa (aparelho ideológico de controle da juventude, criado nos moldes da juventude hitlerista) já enfrentavam um progressivo escaneamento, e as pretensões de absoluto controle ideológico dos aparatos da cultura de massa pretendidas pelos ultracatólicos - que haviam ganho forte impulso na década anterior - também pareciam perder alguma força. Salazar, sempre arbitrando entre as diversas "direitas da direita" (Rosas 2017: 142), parecia naquele momento privilegiar pragmaticamente os setores mais conservadores e menos abertamente fascistas de sua base para atravessar os mares revoltos do pós-guerra.

Ora, se é evidente que isso provocará insatisfação entre a direita mais exaltada (inclusive a ultracatólica), é igualmente evidente que instituições como a censura trabalharão no sentido de policiar a esfera pública para impedir a expressão dessa insatisfação. Não será simples para um Jornal como As Novidades manifestar-se abertamente contra as transigências de Salazar no âmbito de suas políticas de Estado. Por outro lado, o ato de substituir o todo por uma parte - trocando Salazar pelo SNI e toda uma guinada política por uma simples efeméride cultural - torna possível driblar a censura. $\mathrm{O}$ ato de denunciar uma suposta contradição entre o SNI enquanto instituição e sua pretensão de celebrar Eça de Queirós alegando que este seria um envenenador socialista (imoral, ateu, antipatriota, ou como se queira) parece apontar para a contradição muito mais grave que seria o Estado Novo como um todo deixar-se envenenar por esses valores e abandonar seu anti-comunismo, sua moral rígida, seu catolicismo fanático e 
seu nacionalismo intransigente. É neste sentido que, penso, a extrema-direita é a primeira a se aperceber de que o centenário de Eça de Queirós pode transformar-se em uma espécie de esfera pública.

Deixemos essa hipótese em suspenso neste ponto, para abordar outro caso exemplar.

\section{O caso de Rocha Martins}

A partir do ponto em que o SNI se vê forçado a acolher a leitura católica de que apenas o "velho" ou "último" Eça deveria ser celebrado, abre-se uma brecha para todos aqueles que pretendiam fazer uma leitura queirosiana fora dos estreitos limites oficiais do salazarismo: se seu adversário valorizava apenas o velho, tratava-se de louvar o jovem Eça como um anti-salazarista ferrenho. Esta será a estratégia de integrantes do movimento neo-realista, mas também de certos integrantes da chamada oposição moderada, ou republicana. É sobretudo nestes últimos que pretendo focar minha atenção neste texto.

No âmbito do combate à ditadura, e no momento em que o final da Segunda Guerra tornava oportuna a reunião da oposição em torno de uma bandeira pró-democracia, não faltarão leituras enfatizando Eça de Queirós como um "mestre da liberdade intelectual" (Simões 1945: 11), umbilicalmente ligado às lutas contra a repressão autoritária. ${ }^{3}$ Haverá também uma parcela desse grupo que enfatizará além disso as pretensões socializantes da parte do autor. Em um primeiro momento, se tomarmos o ponto de vista da crítica literária uma tal coincidência entre a agenda política e a interpretação literária poderia fazer pensar que os autores em questão estivessem sendo em alguma medida interesseiros, ao instrumentalizar certa interpretação queirosiana para atingir fins políticos específicos. Torna-se tentadora uma leitura semelhante à que fez Miguel Real, segundo o qual estaríamos diante de certo nível de "preconceito ideológico" que turvaria a suposta pureza de uma interpretação literária legítima. Entre os livros que Real critica como padecendo desse mal estão obras canônicas de figuras importantes da crítica lusófona: refiro-me à análise marxista As Ideias de Eça de Queirós, de António José Saraiva, a leitura psicanalista (ainda que precária) levada a cabo por Gaspar Simões em Eça de Queirós: o homem e o artista, e os textos publicados no Livro do Centenário de Eça por António Sérgio (que insere Eça em um debate sobre a educação) e António Cândido (outra análise com laivos marxistas). Numa chave um pouco diferente, podemos falar ainda de Eça de Queirós e a questão social, de Jaime Cortesão. Todos os citados, inclusive o brasileiro Cândido, são opositores do salazarismo e intelectuais simpáticos ao movimento democrático português.

Mas, como já pude dizer, Miguel Real está perdendo algo de vista quando faz sua acusação. O que lhe escapa é o que Fredric Jameson chama de "lugar relacional", isto é, o tipo de diálogo tratado entre esses textos consagrados e seus contextos de origem, apagado pelo fato de sua sobrevivência enquanto clássicos da crítica criar sobre esses livros uma "ilusão de isolamento" (Jameson 1981: 78). O que significava escrever textos como esses em 1945? O debate a respeito de todos e cada um dos textos a que acabo de me referir dependerá de um outro espaço, mais amplo; por ora, entretanto, uma forma possível de reconstituição esse "lugar relacional" talvez seja a partir da análise da atuação na imprensa de um companheiro de fileiras dos autores citados no 
parágrafo acima - isto é, alguém igualmente comprometido com o campo democrático - mas cujo trabalho em torno de Eça de Queirós não se tornou canônico. Refiro-me ao historiador português Francisco Rocha Martins, que já nos últimos anos de sua vida tornou-se um anti-salazarista notório. Penso que um breve olhar sobre o trabalho deste autor acerca de Eça de Queirós baste para que se possa dizer algo mais sobre o que significava fazer uma interpretação anti-salazarista de Eça de Queirós em 1945.

Desde janeiro daquele ano - portanto no mesmo período em que se dava a acesa polêmica entre António Eça e o jornal As Novidades - Rocha Martins começou a publicar nas páginas do Diário de Notícias uma longa série de artigos em torno de Eça. A marca principal dessa série de textos é seu pesado, rigoroso e tedioso trabalho de reconstituição histórica visando tematizar tanto a obra quanto a vida e - principalmente - a genealogia queirosiana. Além disso, é notável, em seu texto, uma quase completa ausência de análise. Temos assim em 14/01 um longo artigo elencando laboriosamente todas as referências ao diabo na obra de Eça (Martins 1945-a). No mês seguinte, Rocha Martins dedica-se a reconstituir historicamente com toda a minúcia - e quase nenhuma reflexão - um encontro havido entre Eça, Oliveira Martins e o Conde de Ficalho (Martins 1945-b). A partir de março, passa a publicar os resultados de sua pesquisa sobre os "românticos antepassados de Eça de Queirós", que acabará por tornar-se um livro com o mesmo título. Escreve na altura sobre "Fernando de Queiroz", um ator nascido ainda em fins do século XVIII que teria sido tio-avô de Eça (Martins, 1945-c), e depois sobre o pai de Eça, autor de um romance histórico intitulado 0 Castelo do Lago (Martins 1945-d). O historicismo insípido desses e de outros textos de Martins torna-os quase indistinguíveis das demais partes do Diário de Notícias que a censura deixava sair.

Entretanto, o leitor que se debruçasse com atenção sobre essas matérias encontraria trechos menos anódinos. No artigo sobre as representações do diabo em Eça de Queirós, um parágrafo perdido entre tantos outros citava as Prosas Bárbaras como um texto em que o "Porco Sujo", o grande vilão da mitologia cristã, aparece como uma espécie de revolucionário: paladino da "liberdade", do "direito humano", incitador de "rebeliões", alguém "bondoso, quase poético" (Martins 1945-a). No esboço biográfico de Fernando de Queiroz, Rocha Martins ressalta o caráter rebelde do ator e sua relação com a censura, através da figura de um censor especialmente ilustrado e gentil (Martins 1945-c). No texto sobre o pai de Eça, ressalta seu perfil romântico e a associação da família às revoltas liberais que atravessaram todo o século XIX (Martins 1945-c). Sempre que pode, mesmo que isso não seja estritamente necessário no âmbito do texto, se refere a Eça como "o autor das Farpas" ou "o autor do Crime do Padre Amaro" (sobretudo em Martins 1945-a), obras que estão entre as mais abertamente anti-sistêmicas da bibliografia queirosiana. É como se, de forma muito esparsa e diluída, em meio a uma massa de texto inócuo, Rocha Martins fosse constituindo um mosaico de referências anti-salazaristas acessível somente aos leitores que se dispusessem a lê-las.

Para que não haja quaisquer dúvidas quanto ao sentido dessas referências soltas, cumpre comparar esses textos do Diário de Notícias com o longo perfil que o historiador escreve sobre Eça para o jornal A República em 16 de novembro daquele mesmo ano (Martins 1945-e). Sendo 
A República um jornal mais combativo, situado um pouco mais claramente no campo da oposição - e sendo novembro um mês em que o governo abrandara a censura para que se pudesse fazer alguma campanha eleitoral durante as eleições para o parlamento (que acabaram se revelando uma fraude) - Rocha Martins escreve agora com singular clareza e veemência. Nele, defende ter encontrado um documento comprobatório do fato de que Eça de Queirós teria permanecido um autor ligado à "liberdade" e à "justiça social" até o fim de sua vida, negando portanto frontalmente a tese oficial de um "último Eça" reacionário. No último parágrafo do texto, Martins anota que "descendente dos rebeldes, o neto do doutor Joaquim de Queiroz, o filho do doutor Teixeira de Queiroz, não podia ser conservador" (Martins 1945-e). Suponho que essa frase seja uma chave para a leitura de toda a produção jornalística anterior de Martins sobre Eça no Diário de Notícias: o estudo genealógico aparentemente anódino e tedioso fora desde o princípio uma tentativa de - através de Eça - falar sobre o liberalismo português e as revoltas democratizantes que o país viveu no século XIX enquanto figuras da liberdade em Portugal. Lembremos que exatamente esse aspecto do século XIX era considerado tabu no Portugal salazarista: o próprio regime, segundo Fernando Rosas, produzia o discurso de que se tratava de um "século negro" em que a nação se divorciara de seu destino imanente, iludida pela sedução liberal (Rosas 2018: 323).

Que Rocha Martins tenha que ter se valido desse expediente extremamente elusivo para disfarçar seu discurso militante dá a medida da sua interdição: em 1945, era necessário escrever sobre a genealogia de Eça de Queirós para que se pudesse veicular ali falas sobre a liberdade no Diário de Notícias. Nesse contexto, não é razoável supor que figuras como Saraiva, Cortesão, Sérgio, Vieira de Almeida e até Gaspar Simões pudessem falar publicamente de suas teorias marxistas e psicanalíticas tomando como objeto Portugal e os portugueses. Eça é, aqui, o que se apresenta como objeto alternativo possível, através do qual os assuntos censurados podem reaparecer deslocados e reestruturados.

\section{Conclusão}

Este pequeno texto, um esforço preliminar de uma pesquisa mais ampla em torno do primeiro centenário de nascimento de Eça de Queirós, buscou ensaiar uma hipótese (a do autor como centro de um debate público no contexto do policiamento da esfera pública) a partir da leitura de certos casos (o de Vieira de Almeida, o do jornal As Novidades e o de Rocha Martins). Parece-me que, pelo menos no âmbito do que foi possível explorar neste artigo, a hipótese se confirma. Em outro artigo, cheguei a uma conclusão semelhante pelo caminho inverso, olhando não para as apropriações não oficiais do centenário de Eça, mas para o fracasso do projeto oficial. O título desse outro texto se refere ao fato de que na cerimônia de encerramento do centenário Ferro lamenta-se pelo fato do debate em torno de Eça ter saído de seu controle e passado a abarcar questões políticas que o Estado novo preferia ver silenciadas. Essa confirmação, por si própria, impõe uma próxima pergunta: porque as estratégias de transformação de Eça no objeto de um debate público deslocado funcionam? Ou, de outro modo: o que há de específico na literatura queirosiana que permite sua apropriação política? 
Esta pergunta, por sua vez, nos remete novamente de volta à dicotomia estabelecida por Miguel Real, entre textos de crítica literária séria e aqueles que padeceriam de um suposto" preconceito ideológico". Isso porque é uma tal indagação que nos permite abandoná-la de vez, quando torna visível o fato de que há sim muito o que se compreender daquilo que há de intrinsecamente literário em um autor como Eça de Queirós a partir de suas leituras politicamente interessadas dizem sobre ele. É uma leitura crítica desses autores que nos permitirá compreender que procedimentos estéticos, formais e temáticos tornam um autor literário apto a funcionar como interface para pensar os fenômenos da política. É o próximo passo que pretendo dar nesta pesquisa.

\title{
NOTAS
}

\begin{abstract}
* Breno Góes é doutorando no Programa de Pós-graduação em Literatura, Cultura e Contemporaneidade da Pontifícia Universidade Católica do Rio de Janeiro (PUC-Rio), orientado pela profa. dra. Izabel Margato. Tem pesquisado desde 2014 as interseções entre a obra de Eça de Queirós e a política. No mestrado e no doutorado, cumpriu porções de sua investigação na Universidade do Porto, sob a supervisão da profa. catedrática Isabel Pires de Lima.
\end{abstract}

${ }^{1}$ Para a natureza do espaço público português durante o salazarismo, cf. Trindade 2011: 43-60.

${ }^{2} \mathrm{O}$ consenso de que a obra de Eça de Queirós poderia ser dividida cronologicamente em duas - consistindo a segunda fase em uma espécie de auto-revisionismo do autor rumo a posições conservadoras ou reacionárias - havia começado a ser estabelecido ainda nas primeiras décadas do século XX, sobretudo por críticos ligados ao nacionalismo português, como Alberto de Oliveira, Fidelino de Figueiredo e Agostinho de Campos.

${ }^{3} \mathrm{O}$ ano de 1945 marca o aparecimento no cenário político português do MUD (Movimento de Unidade Democrática), experiência de frente ampla anti-salazarista que contempla diversos setores da oposição que acaba por ser derrotada e dissolver-se no final da década de 1940 
Cadernos de Literatura Comparada

o Centenário de Eça de Queirós na Imprensa

\section{Bibliografia}

\section{Textos jornalísticos}

(Consultados na Biblioteca municipal do Porto entre janeiro e março de 2020)

"À JANELA de Tormes, pelo professor Vieira de Almeida" (21/11/1945), Diário de Notícias.

"ADESÕES à nossa atitude" (20/01/1945), As Novidades.

"AINDA O CASO nacional de Eça de Queirós" (20/01/1945), As Novidades.

"CONCURSO PARA a ilustração das obras completas de Eça de Queirós" (12/01/1945), As Novidades.

Ferro, António (20/11/1944), "Como se vai celebrar o centenário de Eça de Queirós". [Entrevista concedida ao] Diário de Notícias.

Mantins, Rocha (14/01/1945-a), "O diabo na obra de Eça de Queirós", Diário de Notícias.

- - (10/02/1945-b), "Oliveira Martins e Eça de Queirós descritos pelo Conde de Ficalho", Diário de Notícias.

- - (31/03/1945-c), "Um antepassado de Eça de Queirós", Diário de Notícias.

- - (10/12/1945-d), "Em volta de um livro do pai de Eça de Queirós", Diário de Notícias.

- - (16/11/1945-e), "O espírito da obra do notável romancista", A República.

Qeiroz, António Eça de (19/01/1945-a), "António Eça de Queirós responde às Novidades", As Novidades.

\section{Documentos}

Queiroz, António Eça de, "Procurei comunicar com V. Exa". Carta para Pastor de Macedo [Data: 29/06/1945-b]. Unidade de instalação PT/TT/SNI-GS/28/9, Fundo do SPN/SNI, Arquivo Nacional da Torre do Tombo.

Almeida, Vieira de (1945), À Janela de Tormes, Lisboa, Revista Ocidente. Jameson, Fredric (1981), O Inconsciente Político. São Paulo, Editora Ática.

Lemos, Mario Matos (2019), 1945 - Estado Novo e Oposição. Lisboa, Palimage.

Rosas, Fernando (2018), Salazar e o poder - a arte de saber durar. Lisboa, Tinta da China.

-- (2019), Salazar e os fascismos. Lisboa, Tinta da China.

Safatle, Vladmir (2019), Psicologias do Fascismo. Disponível em <https://www.academia. edu/39801006/Psicologias_do_fascismo___curso_completo_2019_>.(última consulta em 26/01/2021)

Simões, João Gaspar (1945), Eça de Queirós: O homem e o artista. Lisboa, Dois Mundos. Tengarrinha, José (2006), Imprensa e opinião pública em Portugal. Coimbra, Minerva.

Trindade, Luís (2011), "Os excessos de abril", in Margato, Izabel e Gomes, Renato Cordeiro (orgs.), Literatura e revolução. Belo Horizonte, editora UFMG. 